\title{
Use of Rituximab in the Management of Sjögren's Syndrome
}

Francesco Carubbi, MD, PhD ${ }^{1, *}$

Alessia Alunno, $M D^{2}$

Paola Cipriani, $M D^{1}$

Onorina Berardicurti, $M D^{1}$

Piero Ruscitti, $M D^{1}$

Vasiliki Liakouli, $M D^{1}$

Francesco Ciccia, $M D^{3}$

Giovanni Triolo, $M D^{3}$

Roberto Gerli, $M D^{2}$

Roberto Giacomelli, $M D^{1}$

\author{
Address \\ *,1Department of Biotechnological and Applied Clinical Sciences, Rheumatology \\ Unit, University of L'Aquila, 67100, L'Aquila, Italy \\ Email: francescocarubbi@libero.it \\ ${ }^{2}$ Department of Medicine, Rheumatology Unit, University of Perugia, Perugia, \\ Italy \\ ${ }^{3}$ Department of Internal Medicine, Division of Rheumatology \\ University of Palermo, Palermo, Italy
}

Published online: 21 July 2015

(C) Springer International Publishing AG 2015

This article is part of the Topical Collection on Sjögren's Syndrome

Keywords Primary Sjögren's syndrome · B-cells · Biological therapies · Rituximab · Lymphoma

\section{Opinion statement}

Primary Sjögren's syndrome (pSS) is an autoimmune disease, showing a broad heterogeneity concerning the symptoms, the involved organs, as well as the prognosis. The clinical presentation, in the majority of patients, is limited to the mucosal surfaces, although some patients may show a systemic involvement and/or immunological bio-markers strongly associated with a higher risk to develop lymphoma. The assessment of disease activity, by using validated scores, at the time of pSS diagnosis, has been shown to be helpful in identifying patients requiring a closer follow-up and more-intensive therapeutic management. At present, evidence-based therapy for pSS is limited to symptomatic drugs for dryness, and the choice of immunosuppressive or biologic agent treatment is mainly based on their efficacy in other systemic autoimmune diseases, as well as expert opinion 
and uncontrolled studies. In recent years, given the central role of B-lymphocytes in pSS pathogenesis, B-cell depleting therapy with anti-CD20 monoclonal antibody rituximab (RTX) has shown promising, results in clinical trials. Although data present in literature do not allow to draw definitive conclusion on the efficacy of RTX, B-cell depletion may be considered a therapeutic option for a subgroup of pSS patients. In particular, RTX treatment seems to be effective in early active disease, mainly on glandular swelling and in systemic manifestations.

\section{Introduction}

Sjögren's syndrome is a chronic, slowly progressive autoimmune disorder that affects exocrine glands, leading to the sicca complex, a combination of dry eyes (keratoconjunctivitis sicca) and dry mouth (xerostomia). The disease may occur in a primary form, or in a secondary form complicating other autoimmune conditions. Primary Sjögren's syndrome (pSS) is one of the most prevalent autoimmune disorders [1], and the clinical spectrum varies from a benign autoimmune exocrinopathy to a heterogeneous potentially life-threatening systemic disorder, with an increased risk for non-Hodgkin's lymphoma (NHL).

Traditionally, the epithelial cell dysregulation and the aberrant inflammation and autoimmune response are triggered by a combination of genetic and environmental factors involved in PSS pathogenesis. A growing body of evidence has pointed out that B-cells play a central role in the development, maintenance, and progression of the disease, with multiple roles at different points of pSS pathophysiology [2•]. B-lymphocyte hyperactivity, minor salivary gland (MSG) infiltration, and the development of B-cell follicles, containing germinal center (GC)-like structures, represent the hallmarks of the disease [3]. Excessive B-cell activation is responsible for a number of the extraglandular manifestations and serological features of pSS, including hypergammaglobulinemia, cryoglobulinemia, elevated levels of free light chains and $\beta 2$-microglobulin, presence of anti SSA/Ro and SSB/La autoantibodies, or rheumatoid factor (RF), hypocomplementemia, hypergammaglobulinemic purpura, arthritis, vasculitis, neuropathy, and glomerulonephritis [4]. Finally, prolonged B-cell survival and aberrant B-cell activity may lead to the development of NHL in $5 \%$ of pSS patients [5].

Most pSS patients have a clinical pattern mainly dominated by severe dryness, fatigue, and pain which, although not life-threatening, seriously impact on the quality of life [6]. In contrast, systemic involvement plays a key role in the disease prognosis. In particular,
Ioannidis et al. first proposed a prognostic classification, dividing pSS patients into two groups according to the presence or absence of risk factors, as palpable purpura and low C4 levels [7]. Recently, Baldini et al. found that low $\mathrm{C} 3 / \mathrm{C} 4$, hypergammaglobulinaemia, $\mathrm{RF}$, and cryoglobulinaemia are markers of severity in pSS, and the prevalence of the high-risk pSS patient subset for severe systemic manifestations was about $15 \%$ [8]. Quartuccio et al. demonstrated for the first time that among pSS patients with salivary swelling, only those with low C4, cryoglobulins, anti-La antibodies, and leukopenia presented an increased risk of lymphoma evolution [9]. These data suggest three important concepts: (i) the subset of patients at high risk of systemic complications is specifically characterized by an active serological profile, suggestive for B-cell chronic activation; (ii) serological markers of disease severity should be considered in the management of pSS; (iii) patients with this clinical or immunological higher risk pattern should receive a closer follow-up and an earlier and more aggressive immunosuppressive treatment.

To date, therapeutic options for pSS patients are mainly empirical and evidence-based recommendations for the treatment of extraglandular disease manifestations are still lacking [10]. Evidencebased therapy for pSS is mainly limited to symptomatic drugs for dryness, but the treatment with immunosuppressive and biologic agents in pSS, tailored to the organ involvement and the severity, is mainly based on their efficacy in other systemic autoimmune diseases, expert opinion, as well as on uncontrolled studies [11, 12].

In recent years, new biologic drugs have been introduced for the treatment of autoimmune diseases, and, interestingly, most of these target molecules are potentially implicated in pSS pathogenesis. Given the central role of B-lymphocytes in pSS pathogenesis, the most successful results were obtained with B-cell-targeted therapies, and the 
anti-CD20 biologic agent rituximab (RTX), inducing B-cell depletion by several mechanisms, was considered a potential therapeutic option for pSS patients $[13 \bullet]$.
In this review, we will discuss the role of B-cell depleting therapy with anti-CD20 monoclonal antibody RTX in PSS and describe how and why the application of this treatment is still a matter of debate.

\section{Rationale for Targeting B-Cells With RTX In pSS}

RTX is a chimeric (murine/human) monoclonal antibody directly targeting CD20 (human B-lymphocyte-restricted differentiation antigen, Bp35). This molecule is found on the surface of most B-cells, including pre-B and mature Blymphocytes, but not on stem cells, pro-B-cells, normal plasma cells, or other normal tissues [14]. RTX prevents B-cells from proliferating and induces depletion of circulating B-cells from peripheral blood, salivary glands, and other target tissues by complement-mediated cytotoxicity, antibody-dependent cellmediated cytotoxicity, or induction of apoptosis [15]. However, recent studies seem to highlight the role of RTX in modifying the immunological microenvironment of inflamed salivary glands, suggesting new possible mechanisms: (i) reduction of the local expression of IL-22, interfering with the IL-22/IL-22RA1 axis, important in the emergence of $\mathrm{T}$ and B-cell lymphoma [16]; (ii) reduction of the expression of IL-17 and specifically induction of a pronounced apoptotic depletion of mast cells [17]; (iii) reduction of serum levels of different molecules, including granulocyte macrophage colony-stimulating factor (GM-CSF), interleukine (IL)-1Ra, IL-6, IL-10, interferon (IFN) $\alpha$, tumor necrosis factor (TNF) $\alpha$, CCL4, and CXCL9, as indirect effects of B-cell depletion [18]; (iv) induction of a significant decrease of inflammation proteins, cytokines, and growth factors released by epithelial cells, decreasing NF- $\kappa$ B activity and interrupting the NF- $\kappa \mathrm{B}$ signaling pathway through the up-regulation of the Raf1 kinase inhibitor protein [19]; (v) interference with ectopic lymphoneogenesis not only by depleting B-cells but also by tuning the delicate equilibrium between cells, molecules, and receptors, partially affecting the pro-B-cell inflammatory milieu [20•].

\section{Recent Advances and Perspectives on the Use of RTX in pSS}

The only anti-CD20 biologic agent used in pSS is RTX. The two common infusion protocols are a low dose of $375 \mathrm{mg} / \mathrm{m}^{2}$ weekly on day $0,7,12$, and 21 and $1.000 \mathrm{mg}$ on day 1 and day 15 . Although different dosing schedules for RTX have been used in different studies, it can be concluded that RTX induces effective depletion of circulating B-cells in pSS patients and B-cell subset reconstitution pattern with similar kinetics, independently of therapeutic strategies and different dosage [21-23].

RTX was first tested in several open-label studies in pSS, suggesting an improvement of fatigue, sicca symptoms, glandular enlargement, and extraglandular manifestations (Table 1). However, these studies showed how the duration of the clinical effects was rather variable and partially overlapped peripheral blood B-cell depletion. Furthermore, retreatment with RTX resulted in a clinical and biological response comparable to the initial treatment. 
The earliest two small, double-blind randomized studies showed a certain efficacy of RTX in pSS patients. The first, including 17 patients with a median disease duration of 7 years and published in 2008, showed an improvement of fatigue in the RTX-treated group, without any significant change in objective and subjective sicca symptoms after 6 months [33]. The second study, published in 2010 and including 30 patients with a median disease duration of 5 years, showed a significant improvement of stimulated whole saliva flow rate, visual analogical scale (VAS) of sicca symptoms, and a significant reduction of the number of extraglandular manifestations [35]. Although the most pronounced improvement was observed between weeks 12-36, following RTX treatment, at week 48 , the positive effects were lost in all the patients.

However, these results were not recently replicated in a larger placebocontrolled, double-blind trial, the French Tolerance and Efficacy of Rituximab in primary Sjögren syndrome (TEARS) study, [43•]. One hundred and twenty patients with a median disease duration of 5 years, high clinical or serological disease activity, or alternatively, extraglandular manifestations, were allocated to receive one course of RTX or placebo. Although the study failed to reach the primary endpoint (improvement of at least $30 \mathrm{~mm}$ in two of four VAS exploring global activity, fatigue, pain, and dryness, between weeks 0 and 24), several secondary endpoints (dryness and fatigue scores, salivary flow rate, laboratory response) were significantly improved in patients treated with RTX.

Another large randomized controlled trial, namely The Trial of anti-B-cell Therapy in Patients with Primary Sjögren's Syndrome (TRACTISS) study, a phase III study of $110 \mathrm{pSS}$ patients, has been completed in the UK. The TRACTISS treatment regimen comprised two courses of either RTX or placebo, and the outcomes on fatigue, oral dryness, and other glandular manifestations will been reported in autumn 2015 [45]. This study could further provide several information to evaluate efficacy of RTX in pSS, particularly because the study design was intended to be closely aligned to that of the TEARS study, thus allowing subsequent data metaanalysis.

As far as systemic involvement was concerned, Gottenberg et al. demonstrated an improvement of systemic manifestations, including parotid swelling, pulmonary, and articular involvement, 6 months after the first treatment cycle of RTX in a cohort of $78 \mathrm{pSS}$ patients with systemic involvement or severe glandular involvement [42]. In addition, both the median ESSDAI and the median daily dose of prednisone decreased 6 months after RTX administration. Similar results were also observed in uncontrolled studies, especially for articular, vasculitis, as well as for pulmonary and neurological involvement (Table 1).

Meiners and colleagues treated 28 pSS patients with RTX in order to evaluate the responsiveness of the EULAR Sjögren's Syndrome Patient Reported Index (ESSPRI) and ESSDAI [36]. They reported an improvement at week 16 in both ESSDAI and ESSPRI scores, concluding that both these indexes, in particular ESSDAI, display a good sensitivity to change concerning the disease activity after therapeutic intervention.

We recently performed a prospective, multicenter, follow-up study including 41 pSS patients with early (ranging from 6 to 21 months), active disease receiving either RTX or conventional disease modifying anti-rheumatic drugs (DMARDs) plus a stable dose of prednisone [20 $\bullet$. Disease activity was assessed by ESSDAI $\geq 6$ and by values $>50 \mathrm{~mm}$ for 2 of 4 VAS ( 0 to $100 \mathrm{~mm}$ ) items: global disease activity (including extraglandular manifestations), pain, sicca 


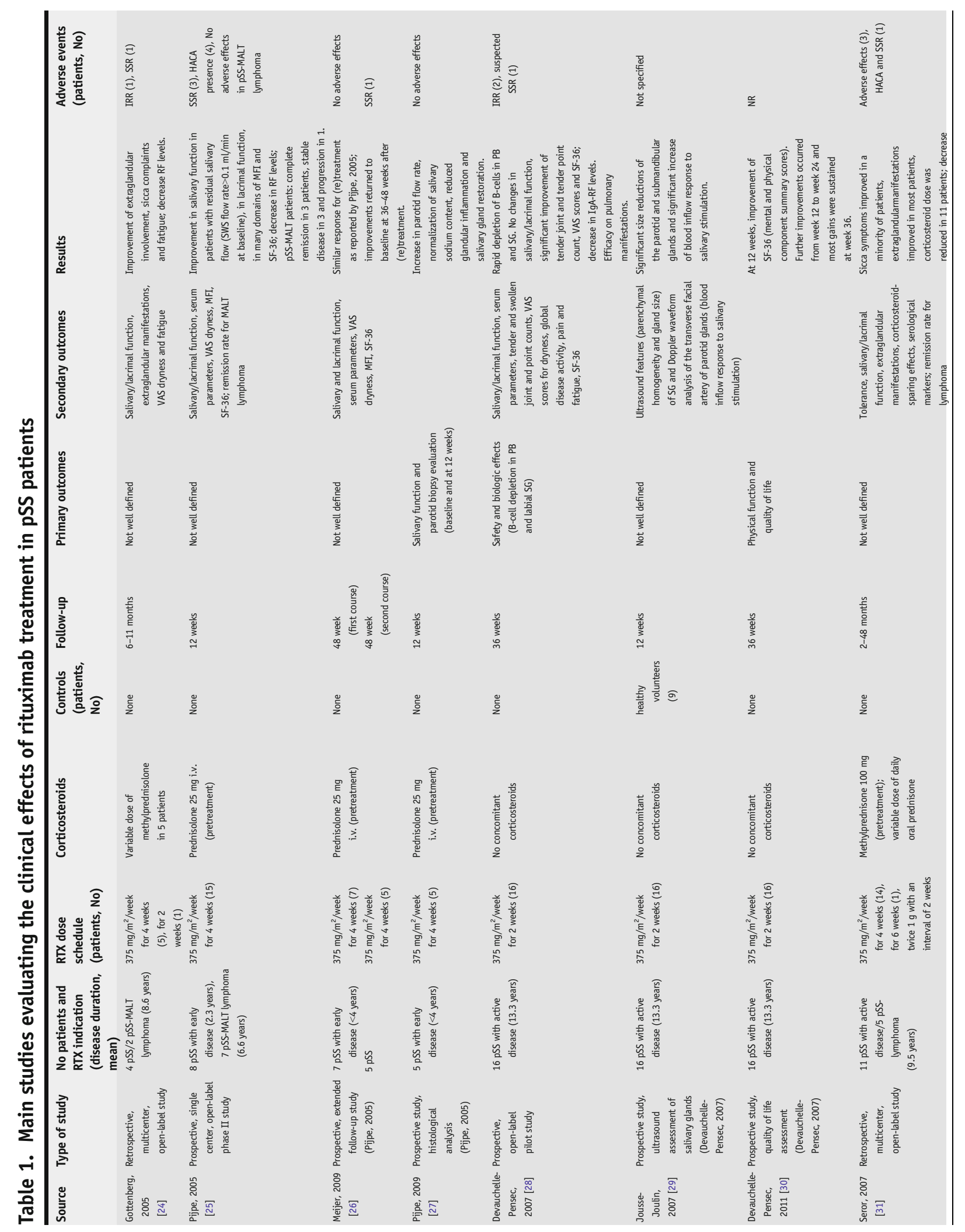




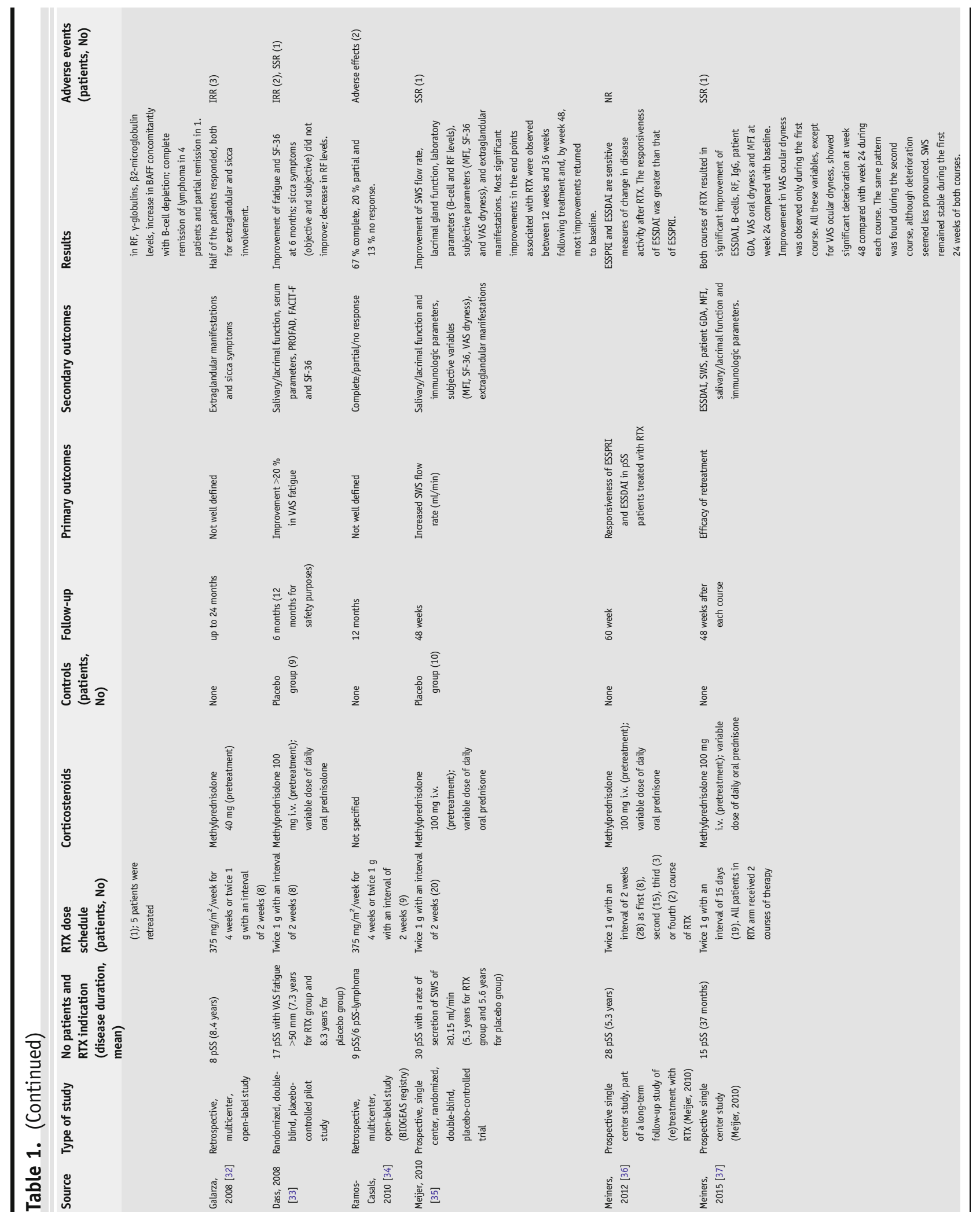




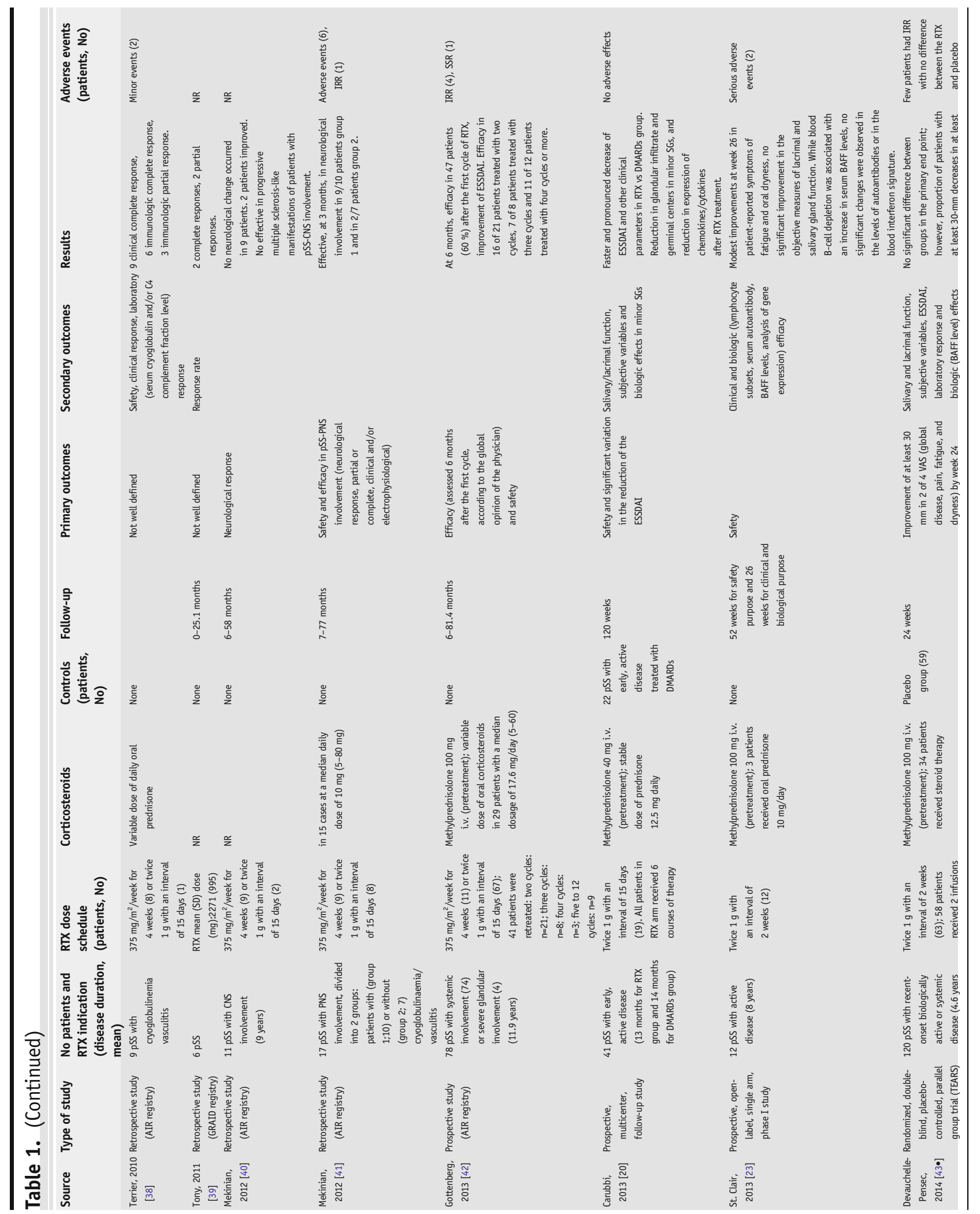




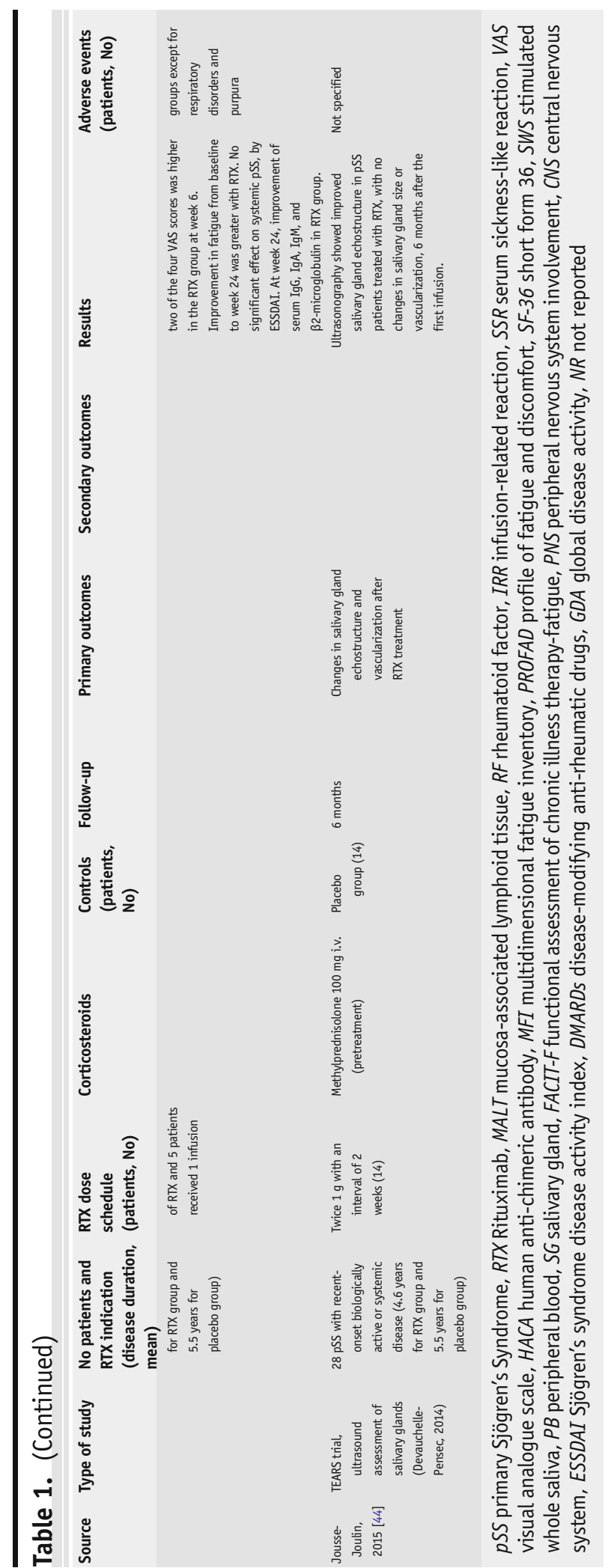


symptoms, and fatigue. Unlike previous studies, pSS patients included in the RTX arm received six courses of therapy (twice $1 \mathrm{~g}$ with an interval of 15 days, every 6 months). We reported a significant improvement in ESSDAI, already from the second course of therapy, which was more pronounced in the RTX arm when compared with the DMARDs arm. This effect was sustained overtime and could be observed throughout the study period. In particular, these data are partially related to a rapid and consistent score reduction of constitutional, lymphadenopathy, glandular, articular, and cutaneous domains. The response curves for VAS global disease activity, VAS pain, VAS fatigue, and physician global assessment mirrored the pattern of ESSDAI. Of interest, a significant improvement in objective (unstimulated salivary flow and Schirmer's test) and histologic (Chisholm and Mason grading and focus score) parameters was also observed in the RTX arm.

Although data present in literature do not allow to draw definitive conclusion on the efficacy of RTX, B-cell depletion may be considered a therapeutic option for selected pSS patients. In particular, RTX treatment seems to be effective in glandular swelling, in some systemic manifestations and in early and active disease. The debate about the real effectiveness of RTX in pSS underscores that the development of sensitive and reproducible outcome measures for pSS are needed as well as further studies on B-cell depletion regimens. To date, the ideal primary endpoint to assess treatment efficacy in pSS remains unknown. Although ESSDAI includes different domains related to the large variability of clinical and laboratory aspects of the disease, it does not incorporate assessments of dryness and has not been extensively validated in controlled trials. Moreover, it should be kept in mind that, although patients included in clinical trials might display the same scores, this does not reflect an overlapping clinical and serological picture. Furthermore, the VAS improvement derived from expert opinion is based on subjective measures and may contribute to the variability of the results. Finally, the optimal RTX regimen required to reach disease improvement in pSS is still unclear.

\section{Retreatment and Safety}

The beneficial effects of RTX in patients with Sjögren's syndrome, when observed, are transient, and responders generally experience a disease relapse. These relapses parallel the B-cell repopulation in the peripheral blood. Furthermore, the local persistence of clonally related Ig-producing B-cells, both in salivary glands and peripheral blood, despite RTX treatment, suggests the lack of a full restoration of the B-cell repertoire to a pre-disease state $[46,47]$. The persistence of B-cell clones may explain the occurrence of relapses after treatment, possibly triggered by additional pathologic stimuli. In particular, B-cell depletion therapy with RTX is followed by an increase of serum B-cell-activating factor (BAFF) levels, inversely correlated to the B-cell number after repopulation, highlighting the role of BAFF both in B-cell homeostasis and in predicting the duration of B-cell suppression [21,48].

On this basis, it may be suggested that pSS patients should be treated either at fixed time-points or, alternatively, according to the circulating B-cell number.

Gottenberg et al. found good physician-reported efficacy and tolerance during retreatment with RTX in 41 initially responding pSS patients [42]. 
Recently, we demonstrated a sustained clinical response and a good safety profile during 6 courses of RTX (given every 24 weeks) in 19 pSS patients with early and active disease [20•]. Meiners and colleagues, analyzing data of 15 pSS patients retreated with RTX after recurrence of symptoms, found comparable beneficial effects as initial treatment on ESSDAI and other objective parameters, whereas the effect on patient-reported parameters was less pronounced [37].

The main goals of retreatment should include both the maintenance of efficacy and the prevention of disease flare. In this context, further studies are needed to investigate both optimal timing of RTX retreatment in pSS patients and the clinical value of a combination therapy, including different biological agents, in a sequential timing.

Unlike in patients with lymphoma or other hematological malignancies, RTX in patients with autoimmune disease does not increase the risk for serious infection [49]. Hypogammaglobulinemia is more likely associated with repeated courses of RTX treatment, although is still not clearly established if the decrease of immunoglobulins, reported in these patients, may be associated with higher risk of infection [50].

We demonstrated that treating our patients for a long period, 120 weeks of RTX administration, in combination with small and stable dosage of prednisone, did not lead to increased adverse events compared to patients treated with DMARDs alone [20•], although acute infusion reactions or serum sickness-like disease have been described in the literature [33, 35, 43•]. Biologic therapies, including RTX, are also potentially associated with an increased risk of progressive multifocal leukoencephalopathy [51]. This is a rare, fatal, central nervous system demyelinating disease that results from reactivation of the JC virus, which usually occurs in immunosuppressed hosts. Although progressive multifocal leukoencephalopathy is rare, the risk of developing this complication must be considered in the decision to use biologic treatments in pSS.

\section{RTX Treatment in pSS-Associated B-Cell Lymphoma}

Non-Hodgkin lymphoma (NHL) is the most severe complication of pSS. In most cases, an extranodal marginal zone of mucosa-associated lymphoid tissue (MALT) lymphoma occurs in pSS target tissues, such as salivary glands. A recent metaanalysis reported that the pooled relative risk (RR), obtained from 11 studies exploring the association of pSS and NHL, is 13.76 (95\% confidence interval (CI) 8.53 to 18.99) compared to the general population [52]. It is to note, however, that at least three issues do not allow to consider such value as a real indicator of NHL risk in worldwide pSS patients. First, a female gender effect should be taken into account considering that the only one study that investigated the risk of NHL in male patients with pSS found no association. [53]. Secondly, studies in non-European countries are few and included small number of patients. Third, the consistent difference between RRs calculated in hospital-based compared to population-based cohorts underscores that the severity of the clinical picture may affect the risk of developing NHL.

Although sharing the same histological features, pSS-associated MALT lymphoma development is different from that affecting patients without pSS. In particular, the crucial event that may promote lymphomagenesis in pSS is the chronic antigenic stimulation, associated with high disease activity. In this 
setting, several studies identified disease specific-clinical and serological predictors of lymphoma such as persistent salivary gland swelling, palpable purpura, cryoglobulinemia, lymphopenia, reduced complement levels and serum/ urine monoclonal component $[7,9,54,55]$. It is worth mentioning that, in recent years, also histological predictors of lymphoma have been identified. In this context, Risselada et al. observed that high values of focus score, namely $\geq 3$, are independent predictor of lymphoma development [56], while Theander et al. reported that GC-like structures were more prevalent in patients who will later developed NHL versus those without subsequent NHL [57]. Taken that GC assessment is not included in routine histological assessment of MSGs at the time of pSS diagnosis, the focus score should be included among "red flags" that allow to identify a pSS patients at high risk of lymphoma.

In addition, the risk of developing lymphoma increases over time and parallels disease duration [55]. This concept further supports the importance of early diagnosis, thorough follow-up, and early treatment of pSS patients that display the aforementioned lymphoma predictors.

Although pSS-associated NHL are often indolent low grade lymphomas, in about $10 \%$ of patients, a transformation towards a diffuse large B-cell lymphoma (DLBCL), thereby worsening disease prognosis, may occur. Therapeutic strategies in pSS-associated NHL are tailored according to the site, type, grade, and extension. RTX plays a major role in the therapeutic regimen of pSSassociated NHL, being at present the best treatment for MALT lymphomas in combination with either alkylating agents, fludarabine, or bendamustine [5860]. Conversely, an association between RTX and CHOP (cyclophosphamide, doxorubicin, vincristine and prednisone) is the best option for the subgroup of patients developing DLBCL [61].

As far as NHL prognosis is concerned, a recent retrospective study of 584 pSS patients followed over a 30-year period (1980-2010) reported 6 death cases among the 53 patients that developed NHL (median follow-up 40.8 months). Patients with MALT lymphoma, the most frequent subtype, were treated with RTX if limited-stage or chemotherapy \pm RTX if disseminated disease. In this subgroup, the 3-year overall survival was $97 \%$ and the 3-year event-free survival $78 \%$. Conversely, a more successful outcome was observed in patients with DLBCL as a $100 \% 3$-year overall survival and event-free survival were achieved with RTX + CHOP therapeutic regimen [62]. These impressive results are in line with a previous study that compared the efficacy of $\mathrm{CHOP}$ alone with respect to RTX + CHOP in pSS patients with DLBCL [61]. A $100 \%$ 2-year overall survival rate was achieved with RTX + CHOP while in the CHOP treatment group only a $37 \%$ survival rate was reported.

Patients with nodal marginal zone lymphomas (NMZLs), which resulted as prevalent as DLBCL (15\% of patients), had a less favorable outcome with a 3year overall survival of $80 \%$ and 3-year event-free survival of $53 \%$ [62].

Importantly, high disease activity, which is a promoter of lymphomagenesis, has been recently associated also with NHL prognosis. In fact, patients with higher disease activity at the time of lymphoma diagnosis had a greater risk for death or for an event, namely lymphoma relapse, treatment failure, disease progression or histological transformation. Therefore, higher disease activity significantly worsened overall survival and event-free survival [63].

Finally, it is worth mentioning that a number of patients with MALT lymphoma, mainly of parotid gland, experience a treatment failure when RTX 


\section{Conclusions}

monotherapy is employed. This issue has been recently addressed by Quartuccio et al. that provided evidence for the involvement of BAFF [64]. In particular, it appeared that the lack of response to RTX may arise from tissue and systemic overexpression of this B-cell related cytokine. In fact, despite B-cell depletion, the microenvironment able to promote their repopulation was maintained overtime. This intriguing evidence may provide the rationale to combine direct B-cell depletion induced by RTX and indirect B-cell targeting employing anti-BAFF antibodies, namely belimumab [65•]. In addition, this novel approach may also allow to avoid chemotherapy in combination with RTX, thereby reducing the burden of adverse events.

Although the use of biologic therapy in pSS is rapidly expanding, with new evidence regarding potential therapeutic targets, it remains difficult to identify which patients will respond and benefit from these treatments. Moreover, biologic therapies are expensive and weighted by potential risk.

B-cell depletion therapy with RTX in pSS has shown conflicting, but promising, results in clinical trials. The heterogeneity of both primary outcomes and selected patients probably accounts for the variability in the results of randomized trials and open-label studies. However, according to previously published data, we can speculate that patients with parotid swelling, extraglandular involvement as well as early and active disease would be the best candidates to receive biologic treatment. Finally, as far as pSS-associated NHL is concerned, case series, case reports, and uncontrolled open-label trials have shown remission of the lymphoma and improvement of the SS-associated signs and symptoms following treatment with RTX.

The failure to achieve consistent clinical benefits with B-cell depletion therapy in some patients may be due to non-B immune abnormalities, an imbalance in $\mathrm{T}$ cell subsets and/or a depletion of regulatory B-cells.

We believe that B-cell depletion may be considered a therapeutic option for selected patients with pSS, and the conflicting results published so far underscore the need to develop sensitive and reproducible outcome measures for pSS and to design additional studies of B-cell depletion strategies.

\section{Compliance with Ethics Guidelines}

\section{Conflict of Interest}

Francesco Carubbi, Alessia Alunno, Paola Cipriani, Onorina Berardicurti, Piero Ruscitti, Vasiliki Liakouli, Francesco Ciccia, Giovanni Triolo, Roberto Gerli, and Roberto Giacomelli declare that they have no conflict of interest.

\section{Human and Animal Rights and Informed Consent}

This article does not contain any studies with human or animal subjects performed by any of the authors. 
Papers of particular of interest, published recently, have been

highlighted as:

- Of importance

1. Patel R, Shahane A. The epidemiology of Sjögren's syndrome. Clin Epidemiol. 2014;6:247-55.

2. $\quad$ Kroese FG, Abdulahad WH, Haacke E, Bos NA, Vissink A, Bootsma H. B-cell hyperactivity in primary Sjögren's syndrome. Expert Rev Clin Immunol. 2014;10:483-99.

The most comprehensive review concerning the role of B-cells in pSS pathogenesis.

3. Carubbi F, Alunno A, Cipriani P, Di Bendetto P, Ruscitti $\mathrm{P}$, Berardicurti $\mathrm{O}$, et al. Is minor salivary gland biopsy more than a diagnostic tool in primary Sjögren's syndrome? Association between clinical, histopathological, and molecular features: a retrospective study. Semin Arthritis Rheum. 2014;4:314-24.

4. Voulgarelis M, Tzioufas AG. Pathogenetic mechanisms in the initiation and perpetuation of Sjögren's syndrome. Nat Rev Rheumatol. 2010;6:529-37.

5. Nocturne G, Mariette X. Advances in understanding the pathogenesis of primary Sjögren's syndrome. Nat Rev Rheumatol. 2013;9:544-56.

6. Lendrem D, Mitchell S, McMeekin P, Bowman S, Price E, Pease CT, et al. Health-related utility values of patients with primary Sjögren's syndrome and its predictors. Ann Rheum Dis. 2014;73:1362-8.

7. Ioannidis JP, Vassiliou VA, Moutsopoulos HM. Longterm risk of mortality and lymphoproliferative disease and predictive classification of primary Sjögren's syndrome. Arthritis Rheum. 2002;46:741-7.

8. Baldini C, Pepe P, Quartuccio L, Priori R, Bartoloni E, Alunno A, et al. Primary Sjögren's syndrome as a multiorgan disease: impact of the serological profile on the clinical presentation of the disease in a large cohort of Italian patients. Rheumatology (Oxford).

2014;53:839-44.

9. Quartuccio L, Isola M, Baldini C, Priori R, Bartoloni Bocci E, Carubbi F, et al. Biomarkers of lymphoma in Sjögren's syndrome and evaluation of the lymphoma risk in prelymphomatous conditions: results of a multicenter study. J Autoimmun. 2014;51:75-80.

10. Ramos-Casals M, Brito-Zeron P, Sisó-Almirall A, Bosch $\mathrm{X}$, Tzioufas AG. Topical and systemic medications for the treatment of primary Sjögren's syndrome. Nat Rev Rheumatol. 2012;8:399-411.

11. Ramos-Casals M, Tzioufas AG, Stone JH, Sisó A, Bosch $\mathrm{X}$. Treatment of primary Sjögren's syndrome: a systematic review. JAMA. 2010;304:452-60.

12. Brito-Zeron P, Sisó-Almirall A, Bové A, Kostov BA, Bamos-Casals M. Primary Sjögren's syndrome: an update on current pharmacotherapy options and future directions. Expert Opin Pharmacother. 2013;14:279-89.

13. Carubbi F, Alunno A, Cipriani P, Bartoloni E, Ciccia F, Triolo G, et al. Rituximab in primary Sjögren's syndrome: a ten-year journey. Lupus. 2014;23:1337-49.
The most comprehensive, independent review of the subject.

14. Pescovitz MD. Rituximab, an anti-CD20 monoclonal antibody: history and mechanism of action. Am J Transplant. 2006;6:859-66.

15. Perosa F, Prete M, Racanelli V, Dammacco F. CD20depleting therapy in autoimmune diseases: from basic research to the clinic. J Intern Med. 2010;267:260-77.

16. Ciccia F, Giardina A, Rizzo A, Guggino G, Cipriani P, Carubbi F, et al. Rituximab modulates the expression of IL-22 in the salivary glands of patients with primary Sjögren's syndrome. Ann Rheum Dis. 2013;72:782-3.

17. Ciccia F, Guggino G, Rizzo A, Alessandro R, Carubbi F, Giardina A, et al. Rituximab modulates IL-17 expression in the salivary glands of patients with primary Sjögren's syndrome. Rheum (Oxford). 2014;53:1313-20.

18. Pollard RP, Abdulahad WH, Bootsma H, Meiners PM, Spijkervet FK, Huitema MG, et al. Predominantly proinflammatory cytokines decrease after B cell depletion therapy in patients with primary Sjögren's syndrome. Ann Rheum Dis. 2013;72:2028-50.

19. Lisi S, Sisto M, D'Amore M, Lofrumento DD. Coculture system of human salivary gland epithelial cells and immune cells from primary Sjögren's syndrome patients: an in vitro approach to study the effects of Rituximab on the activation of the Raf-1/ERK1/2 pathway. Int Immunol. 2015;27:183-94.

20. Carubbi F, Cipriani P, Marrelli A, Di Bendetto P, Ruscitti P, Berardicurti O, et al. Efficacy and safety of rituximab treatment in early primary Sjögren's syndrome: a prospective, multicenter, follow-up study. Arthritis Res Ther. 2013;15:R172.

This paper demonstrates biological effects of the drug and long-term safety of treatment.

21. Pers JO, Devauchelle V, Daridon C, Bendaoud B, Berre $\mathrm{R}$, Bordron A, et al. BAFF-modulated repopulation of $\mathrm{B}$ lymphocytes in the blood and salivary glands of rituximab-treated patients with Sjögren's syndrome. Arthritis Rheum. 2007;56:1464-77.

22. Abdulahad WH, Meijer JM, Kroese FG, Meiners PM, Vissink A, Spijkervet FK, et al. B cell reconstitution and Thelper cell balance after rituximab treatment of active primary Sjögren's syndrome: A double-blind, placebocontrolled study. Arthritis Rheum. 2011;63:1116-23.

23. St Clair EW, Levesque MC, Prak ET, Vivino FB, Alappatt CJ, Spychala ME, et al. Rituximab therapy for primary Sjögren's syndrome: an open-label clinical trial and mechanistic analysis. Arthritis Rheum. 2013;65:1097-106.

24. Gottenberg JE, Guillevin L, Lambotte O, Combe B, Allanore Y, Cantagrel A, et al. Tolerance and short term efficacy of rituximab in 43 patients with systemic autoimmune diseases. Ann Rheum Dis. 2005;64:913-20. 
25. Pijpe J, van Imhoff GW, Spijkervet FK, et al. Rituximab treatment in patients with primary Sjögren's syndrome: an open-label phase II study. Arthritis Rheum. 2005;52:2740-50.

26. Meijer JM, Pijpe J, Vissink A, Kallenberg CG, Bootsma H. Treatment of primary Sjögren's syndrome with rituximab: extended follow-up, safety and efficacy of retreatment. Ann Rheum Dis. 2009;68:284-5.

27. Pijpe J, Meijer JM, Bootsma H, van der Wal JE, Spijkervet FK, Kallenberg CG, et al. Clinical and histologic evidence of salivary gland restoration supports the efficacy of rituximab treatment in Sjögren's syndrome. Arthritis Rheum. 2009;60:3251-6.

28. Devauchelle-Pensec V, Pennec Y, Morvan J, Pers JO, Daridon C, Jousse-Joulinet S, et al. Improvement of Sjögren's syndrome after two infusions of rituximab (anti-CD20). Arthritis Rheum. 2007;57:310-7.

29. Jousse-Joulin S, Devauchelle-Pensec V, Morvan J, Guias B, Pennec Y, Pers JO, et al. Ultrasound assessment of salivary glands in patients with primary Sjögren's syndrome treated with rituximab: quantitative and Doppler waveform analysis. Biologics. 2007;1:311-9.

30. Devauchelle-Pensec V, Morvan J, Rat AC, Jousse-Joulin S, Pennec Y, Pers JO, et al. Effects of rituximab therapy on quality of life in patients with primary Sjögren's syndrome. Clin Exp Rheumatol. 2011;29:6-12.

31. Seror R, Sordet C, Guillevin L, Hachulla E, Masson C, Ittah $\mathrm{M}$, et al. Tolerance and efficacy of rituximab and changes in serum B cell biomarkers in patients with systemic complications of primary Sjögren's syndrome. Ann Rheum Dis. 2007;66:351-7.

32. Galarza C, Valencia D, Tobon GJ, Zurita L, Mantilla RD, Pineda-Tamayo R, et al. Should rituximab be considered as the first-choice treatment for severe autoimmune rheumatic diseases? Clin Rev Allergy Immunol. 2008;34:124-8.

33. Dass S, Bowman SJ, Vital EM, Ikeda K, Pease CT, Hamburger J, et al. Reduction of fatigue in Sjögren's syndrome with rituximab: results of a randomised, double-blind, placebo-controlled pilot study. Ann Rheum Dis. 2008;67:1541-4.

34. Ramos-Casals M, Garcia-Hernandez FJ, de Ramon E, Callejas JL, Martínez-Berriotxoa A, Pallarés L, et al. Offlabel use of rituximab in 196 patients with severe, refractory systemic autoimmune diseases. Clin Exp Rheumatol. 2010;28:468-76.

35. Meijer JM, Meiners PM, Vissink A, Spijkervet FK, Abdulahad W, Kamminga N, et al. Effectiveness of rituximab treatment in primary Sjögren's syndrome: a randomized, double-blind, placebo-controlled trial. Arthritis Rheum. 2010;62:960-8.

36. Meiners PM, Arends S, Brouwer E, Spijkervet FK, Vissink A, Bootsma H. Responsiveness of disease activity indices ESSPRI and ESSDAI in patients with primary Sjögren's syndrome treated with rituximab. Ann Rheum Dis. 2012;71:1297-302.

37. Meiners PM, Arends S, Meijer JM, Moerman RV, Spijkervet FK, Vissink A, Bootsma H. Efficacy of retreatment with rituximab in patients with primary Sjögren's syndrome. Clin Exp Rheumatol. 2015.

38. Terrier B, Launay D, Kaplanski G, Hot A, Larroche C, Cathébras $P$, et al. Safety and efficacy of rituximab in nonviral cryoglobulinemia vasculitis: data from the French Autoimmunity and Rituximab registry. Arthritis Care Res (Hoboken). 2010;62:1787-95.

39. Tony HP, Burmester G, Schulze-Koops H, Grunke M, Henes J, Kötter I, et al. Safety and clinical outcomes of rituximab therapy in patients with different autoimmune diseases: experience from a national registry (GRAID). Arthritis Res Ther. 2011;13:R75.

40. Mekinian A, Ravaud P, Larroche C, Hachulla E, Gombert B, Blanchard-Delaunay C, et al. Rituximab in central nervous system manifestations of patients with primary Sjögren's syndrome: results from the AIR registry. Clin Exp Rheumatol. 2012;30:208-12.

41. Mekinian A, Ravaud P, Hatron PY, Larroche C, Leone J, Gombert B, et al. Efficacy of rituximab in primary Sjögren's syndrome with peripheral nervous system involvement: results from the AIR registry. Ann Rheum Dis. 2012;71:84-7.

42. Gottenberg JE, Cinquetti G, Larroche C, Combe B, Hachulla E, Meyer O, et al. Efficacy of rituximab in systemic manifestations of primary Sjögren's syndrome: results in 78 patients of the autoimmune and rituximab registry. Ann Rheum Dis. 2013;72:1026-31.

43. Devauchelle-Pensec V, Mariette X, Jousse-Joulin S, Berthelot JM, Perdriger A, Puéchal X, et al. Treatment of primary Sjögren's syndrome with rituximab: a randomized trial. Ann Intern Med. 2014;160:233-42.

This study failed to show benefit for rituximab in a major clinical trial.

44. Jousse-Joulin S, Devauchelle-Pensec V, Cornec D, Marhadour T, Bressollette L, Gestin S, et al. Ultrasonographic salivary gland response to rituximab in primary Sjögren's syndrome. Arthritis Rheumatol. 2015. doi:10. 1002/art.39088.

45. Brown S, Navarro Coy N, Pitzalis C, Emery P, Pavitt S, Gray J, et al. The TRACTISS protocol: a randomized double blind placebo controlled clinical trial of anti-Bcell therapy in patients with primary Sjögren's Syndrome. BMC Musculoskelet Disord. 2014;15:21.

46. Hamza N, Bootsma H, Yuvaraj S, Spijkervet FK, Haacke EA, Pollard RP, et al. Persistence of immunoglobulinproducing cells in parotid salivary glands of patients with primary Sjögren's syndrome after B cell depletion therapy. Ann Rheum Dis. 2012;71:1881-7.

47. Hershberg U, Meng W, Zhang B, Haff N, St Clair EW, Cohen PL, et al. Persistence and selection of an expanded B cell clone in the setting of rituximab therapy for Sjögren's syndrome. Arthritis Res Ther. 2014;16:R51.

48. Pollard RP, Abdulahad WH, Vissink A, Hamza N, Burgerhof JG, Meijer JM, et al. Serum levels of BAFF, but not APRIL, are increased after rituximab treatment in patients with primary Sjögren's syndrome: data from a placebo-controlled clinical trial. Ann Rheum Dis. 2013;72:146-8. 
49. Chen S, Liu Y, Shi G. Anti-CD20 antibody in primary Sjögren's syndrome management. Curr Pharm Biotechnol. 2014;15:535-41.

50. Bowman S, Barone F. Biologic treatments in Sjögren's syndrome. Presse Med. 2012;41:e495-509.

51. Bharat A, Xie F, Baddley JW, Beukelman T, Chen L, Calabrese $\mathrm{L}$, et al. Incidence and risk factors for progressive multifocal leukoencephalopathy among patients with selected rheumatic diseases. Arthritis Care Res. 2012;64:612-5.

52. Liang Y, Yang Z, Qin B, Zhong R. Primary Sjögren's syndrome and malignancy risk: a systematic review and meta-analysis. Ann Rheum Dis. 2014;73:1151-6.

53. Weng MY, Huang YT, Liu MF, Lu TH. Incidence of cancer in a nationwide population cohort of 7852 patients with primary Sjögren's syndrome in Taiwan. Ann Rheum Dis. 2012;71:524-7.

54. Theander E, Henriksson G, Ljungberg O, Mandl T, Manthorpe R, Jacobsson LT. Lymphoma and other malignancies in primary Sjögren's syndrome: a cohort study on cancer incidence and lymphoma predictors. Ann Rheum Dis. 2006;65:796-803.

55. Solans-Laqué R, López-Hernandez A, Bosch-Gil JA, Palacios A, Campillo M, Vilardell-Tarres M. Risk, predictors, and clinical characteristics of lymphoma development in primary Sjögren's syndrome. Semin Arthritis Rheum. 2011;41:415-23.

56. Risselada AP, Kruize AA, Goldschmeding R, Lafeber FP, Bijlsma JW, van Roon JA. The prognostic value of routinely performed minor salivary gland assessments in primary Sjögren's syndrome. Ann Rheum Dis. 2014;73:1537-40.

57. Theander E, Vasaitis L, Baecklund E, Nordmark G, Warfvinge $G$, Liedholm R, et al. Lymphoid organisation in labial salivary gland biopsies is a possible predictor for the development of malignant lymphoma in primary Sjögren's syndrome. Ann Rheum Dis. 2011;70:1363-8.

58. Rummel MJ, Niederle N, Maschmeyer G, Banat GA, von Grünhagen $\mathrm{U}$, Losem $\mathrm{C}$, et al. Bendamustine plus rituximab versus $\mathrm{CHOP}$ plus rituximab as firstline treatment for patients with indolent and mantle-cell lymphomas: an open-label, multicentre, randomised, phase 3 non-inferiority trial. Lancet. 2013;381:1203-10.

59. Saadoun D, Pineton de Chambrun M, Hermine $O$, Karras A, Choquet S, Jego P, et al. Using rituximab plus fludarabine and cyclophosphamide as a treatment for refractory mixed cryoglobulinemia associated with lymphoma. Arthritis Care Res (Hoboken). 2013;65:643-7.

60. Zucca E, Conconi A, Laszlo D, López-Guillermo A, Bouabdallah R, Coiffier B, et al. Addition of rituximab to chlorambucil produces superior event-free survival in the treatment of patients with extranodal marginalzone B-cell lymphoma: 5-year analysis of the IELSG-19 Randomized Study. J Clin Oncol. 2013;31:565-72.

61. Voulgarelis M, Giannouli S, Tzioufas AG, Moutsopoulos HM. Long term remission of Sjögren's syndrome associated aggressive B cell non-Hodgkin's lymphomas following combined B cell depletion therapy and CHOP (cyclophosphamide, doxorubicin, vincristine, prednisone). Ann Rheum Dis. 2006;65:1033-7.

62. Voulgarelis M, Ziakas PD, Papageorgiou A, Baimpa E, Tzioufas AG, Moutsopoulos HM. Prognosis and outcome of non-Hodgkin lymphoma in primary Sjögren syndrome. Medicine (Baltimore). 2012;91:1-9.

63. Papageorgiou A, Ziogas DC, Mavragani CP, Zintzaras E, Tzioufas AG, Moutsopoulos HM, et al. Predicting the outcome of Sjogren's syndrome-associated nonHodgkin's lymphoma patients. PLoS One. 2015;10, e0116189.

64. Quartuccio L, Fabris M, Moretti M, Barone F, Bombardieri M, Rupolo M, et al. Resistance to rituximab therapy and local BAFF overexpression in Sjögren's syndrome-related myoepithelial sialadenitis and low-grade parotid B-cell lymphoma. Open Rheumatol J. 2008;2:38-43.

65. De Vita S, Quartuccio L, Salvin S, Picco L, Scott CA, Rupolo M, et al. Sequential therapy with belimumab followed by rituximab in Sjögren's syndrome associated with B-cell lymphoproliferation and overexpression of BAFF: evidence for long-term efficacy. Clin Exp Rheumatol. 2014;32:490-4.

This paper suggests the benefit of a sequential therapy with belimumab and rituximab. 